\title{
LUGARES DE RESISTÊNCIA: O PROCESSO DE REPRODUÇÃO DO ESPAÇO URBANO NO CONTEXTO DOS MEGAEVENTOS ESPORTIVOS NO BRASIL - SÃO PAULO E RIO DE JANEIRO
}

\author{
Places of resistance: the process of reprodutction of urban space in the context of sports mega events in \\ Brazil - São Paulo and Rio de Janeiro \\ Carine Botelho Previatti* \\ *Doutoranda no PPG em Geografia Humana - FFLCH/USP - cbpreviatti@gmail.com.
}

Recebido em 15/05/2018. Aceito para publicação em 25/06/2018.

Versão online publicada em 10/08/2018 (http://seer.ufrgs.br/paraonde)

\begin{abstract}
Resumo: Em todas as grandes cidades do mundo, fragmentos do espaço são escolhidos para receber aportes de capital sobre o interesse de alguns grupos em detrimento de outros, usando os megaeventos esportivos como justificativa e sinalizando um novo processo de reprodução do capitalismo nos tempos contemporâneos, que traz à tona o conflito pelo espaço - como lugar de apropriação e uso em contraposição ao espaço como reprodução de valor e de valor de troca. Objetiva-se analisar o conflito pelo espaço urbano em relação à habitação e as formas de resistência dos moradores que foram diretamente afetados por obras de infraestrutura e construção de equipamentos para os megaeventos esportivos brasileiros - Copa do Mundo 2014 e Jogos Olímpicos Rio 2016 -, tendo o poder público como intermediador dos processos de remoção e as empresas privadas como responsáveis pela execução das obras públicas. A metodologia teórica proposta se baseia na análise dos níveis e dimensões propostos por Lefebvre $(2001,2002)$, representados pelo embate constante entre a ordem próxima ou nível imediato (o vivido), e a ordem distante (as instituições), mediada pelo nível intermediário (a cidade). A metodologia prática que se coloca é a aplicação de entrevistas dirigidas à moradores das comunidades que foram ameaçadas de remoção, tanto com os que conseguiram permanecer quanto com os que aceitaram as negociações com o poder público. Almeja-se discutir as resistências por habitação dentro de um contexto historicamente produzido e tendo por premissa que o próprio processo de resistência é a forma possível encontrada por muitos moradores das metrópoles, na busca por uma utopia de transformação da própria relação social e do modo como se produzem os espaços.
\end{abstract}

Palavras-chave: Resistência social, Segregação socioespacial, Megaeventos esportivos.

\begin{abstract}
In all the major cities of the world, fragments of space are chosen to receive capital injections in interest of some groups over others, using sports mega-events as a justification and signaling a fundamental moment in the process of reproduction of capitalism in contemporary times, which brings the conflict over space - as a place of appropriation and use and contrast of the space as reproduction of value and wealth. This work aims to analyze the conflict over the urban space in relation to housing and resistance of the residents of four Brazilian communities, two in the city of São Paulo and two in Rio de Janeiro, which were directly affected by the infrastructure and equipment construction for the 2014 World Cup and Rio 2016 Olympic Games. The proposed theoretical methodology is based on the analysis of the levels and dimensions of Lefebvre $(2001,2002)$, represented by the constant brunt between the local order or immediate level (the lived level), and the distant order (the institutions), mediated by the intermediate level (the city). The practical methodology that is applied is the application of directed interviews to the residents of the communities who were threatened with removal, both with those who managed to remain and with those who accepted the negotiations with the public power. It is hoped to discuss the resistances for housing within a historically produced context and assuming that the resistance process itself is the possible form found by many inhabitants of the metropolises, in the search for a utopia of transformation of the social relation and the way in which spaces are produced.
\end{abstract}

Key-words: Social resistance, socio-spatial segregation, sport mega-events. 


\title{
1. Introdução
}

Ao longo da pesquisa realizada no Mestrado, que tinha por objetivo explicitar os processos históricos que causaram a remoção da comunidade Vila Autódromo, localizada na zona oeste da cidade do Rio de Janeiro, para a realização de obras de infraestrutura na construção do Parque Olímpico dos Jogos Rio-2016, algumas questões mais amplas surgiram, principalmente sobre as mudanças sociais ocorridas dentro do processo de luta pela permanência. A necessidade diária dos residentes em conciliar suas vidas pessoais com a constante tentativa de remoção pelo poder público, as diversas formas de articulação política desenvolvidas pelos moradores e, principalmente, o processo de conscientização social, econômica e política que a luta proporcionou a alguns deles, foram algumas dessas questões.

Nesse sentido, a pesquisa proposta se orientará no movimento de uma leitura geográfica que compreende a produção do espaço urbano, principalmente das grandes cidades, como central para a reprodução social no que tange ao seu valor de troca, presente nos processos de acumulação e no seu valor de uso, no plano do cotidiano, contrapostos ao uso desses espaços praticados pelos moradores no plano do vivido.

Nessa perspectiva, julgou-se essencial, primeiramente, entender a centralidade que assume o processo de reprodução das metrópoles para a própria reprodução do capital, aprofundando as contradições e conflitos entre os ditames do processo de acumulação e as necessidades e desejos que se colocam no âmbito da reprodução da vida social. Como pressuposto desta discussão, está a compreensão do espaço como condição, meio e produto da sociedade, como discute Carlos (2011), ou seja, o espaço pensado como produto social, realizado através do trabalho historicamente construído e que se materializa para o uso e a apropriação diversos, em diferentes momentos históricos.

\begin{abstract}
Espaço entendido aqui como produto histórico e social, produto e condição de práticas e relações sociais que são, também, espaciais. A noção de produção que tem no trabalho categoria central ultrapassa, no entanto, o sentido estrito da produção de bens e objetos, para alcançar um significado amplo, que abarca a produção de relações sociais e de produção de valores, de representações, da vida em todas as suas dimensões (Alvarez, 2008, p.12).
\end{abstract}

O espaço produzido é assim também condição da reprodução social e o meio pela qual ela se realiza. No capitalismo, este processo é determinado pelos interesses ligados à reprodução do capital, onde o uso do espaço é pautado pelas relações do valor de troca, das mercadorias e da propriedade privada do solo urbano, em detrimento ao valor de uso, da reprodução da vida social.

Lefebvre (2016), em um prolongamento da obra de Karl Marx, foi um dos primeiros pensadores a reconhecer o processo de produção do espaço no âmbito da economia política. Para o autor, existe um momento na história do processo de produção capitalista onde o sistema fordista entra em crise e precisa criar uma nova forma de investir o excedente da produção, que seria gestada pela tríade: urbano, espaço e cotidiano. A partir do materialismo dialético, o autor formulou a hipótese de que houve uma expansão do processo capitalista de produção-distribuição-circulação-troca para abarcar todos os setores da vida social, agora pautadas pela forma mercadoria, como já previa Marx (1978).

O conflito pelo espaço se agrava através dos processos de segregação socioespaciais pautadas pela propriedade privada, que impede que grande parte da população possa habitar de forma digna ou usufruir do espaço nas cidades. Essa segregação nega o valor de uso da habitação, o cotidiano e os modos de vida, que são suplantados pela lógica do consumo, o valor de troca.

A análise da dialética do espaço, nessa perspectiva analítica, pode ser apreendida através dos níveis de contradição que são inerentes ao próprio espaço. Para Lefebvre (2001), esses níveis de contradição seriam representados pelo embate constante entre a ordem próxima ou nível imediato 
(o vivido), e a ordem distante (as instituições), mediada pelo nível intermediário (a cidade). "É justamente quando o vivido é substituído pelo concebido que a representação se torna ideologia" (Serpa, 2014, p.487).

As contradições do espaço não advêm de sua forma racional, tal como ela se revela na matemática. Elas advêm do conteúdo prático e social e, especificamente, do conteúdo capitalista. Como efeito, o espaço da sociedade capitalista pretende-se racional quando, na prática, é comercializado, despedaçado, vendido em parcelas. Assim, ele é simultaneamente global e pulverizado. Ele parece lógico e é absurdamente recortado. Essas contradições explodem no plano institucional. Nesse plano, percebe-se que a burguesia, classe dominante, dispõe de um duplo poder sobre o espaço; primeiro, pela propriedade privada do solo, que se generaliza por todo o espaço, com exceção dos direitos das coletividades e do Estado. Em segundo lugar, pela globalidade, a saber, o conhecimento, a estratégia, a ação do próprio Estado. Existem conflitos inevitáveis entre esses dois aspectos, e notadamente entre o espaço abstrato (concebido ou conceitual, global e estratégico) e o espaço imediato percebido, vivido, despedaçado e vendido [...] (Lefebvre, 2016, p.55).

Seguindo essa linha de pensamento de Lefebvre (2001), é pelo espaço e no espaço onde, dialeticamente, se inscrevem as relações conflitantes entre os níveis, que se interconectam ao se realizarem. Portanto, as contradições se apresentam de forma mais acentuada, o que salienta a importância metodológica já defendida por esse autor, sobre como a percepção da realidade está pautada na prática. Por essa análise, o espaço, por ser produto social, se torna uma mercadoria que, pela análise marxista, vira uma abstração, um espaço padronizado e voltado para o consumo, a propriedade privada e o individualismo.

0 protagonismo do espaço urbano dentro da economia mundial retrata um momento crucial da própria produção capitalista, que passa em diversas partes do mundo, por uma transição do capital industrial para o capital financeiro, tendo por premissa, a reprodução continuada de espaços dentro das cidades, que atendem a essa nova característica política, econômica e principalmente social. Como reflete Carlos (2015, p.15):

Todavia, o processo de produção do espaço, na qualidade de processo civilizatório, traz em si aquilo que o nega, isto é, com o desenvolvimento do capitalismo, o espaço (produção social) torna-se uma mercadoria, como todos os produtos do trabalho humano. Nessa condição, revela-se, no plano da vida pela contradição valor de uso/valor de troca. A extensão do capitalismo tomou o espaço, fez dele sua condição de produção, primeiro como recurso, depois como força produtiva, e finalmente como mercadoria reprodutível, através do setor imobiliário. Seu movimento em direção à sua reprodução aponta o urbano. Aqui os planos da realidade - econômico, político, social - se imbricam, e as escalas - do local ao mundial - se justapõem esclarecendo sujeitos produtores do espaço e seus processos constitutivos.

Dessa forma, é possível compreender que, segundo reflexões de Lefebvre (1973), existe um processo de homogeneização do urbano num plano global, representado pelas estruturas iguais que seriam produzidas no espaço em todas as partes do mundo e que tenderiam a criar um consumo repetitivo do espaço, tais como grandes conjuntos habitacionais verticais, aeroportos, rodovias. Esse espaço que se pretende homogêneo é fragmentado em pedaços, ou seja, a separação de pedaços desse espaço maior por funções específicas, predeterminadas para o cotidiano das pessoas: o lugar para trabalhar, o lugar para o lazer, o lugar para o morar. Essa divisão do espaço auxilia no seu controle pelo Estado, ao passo que se pretende racional e quantificável e na sua melhor distribuição para as empresas e o mercado. Lefebvre (1973) chega, portanto, a uma contradição desse modelo de produção, pois, ao mesmo tempo que se pretende uma homogeneização e uma racionalização funcional do espaço, esse mesmo processo acaba por criar sua própria fragmentação. 
A reprodução de espaços, ao mesmo tempo homogêneos e fragmentados, só é possível através das forças e ações políticas que, racionalmente e quantitativamente, difundem o próprio ciclo de acumulação do capital no e pelo espaço. Os fragmentos do espaço acabam sendo hierarquizados por conta de suas funções preestabelecidas, determinando o lugar de cada um na cidade, delineando a segregação socioespacial e a dissolução das relações sociais, tendo a propriedade privada papel fundamental nesse processo. Nessa perspectiva, o valor de troca subjaz o uso também na reprodução da cidade, principalmente através da apropriação privada sobre uma construção social, trazendo à tona a discussão, já presente em Marx (1978) sobre a restruturação das relações de produção, abarcando todos os momentos da vida.

\begin{abstract}
A segregação é a negação do urbano e da vida urbana. Seu fundamento é a existência da propriedade privada do solo urbano, que diferencia o acesso do cidadão à moradia, produzindo a fragmentação dos elementos da prática socioespacial urbana e separando os lugares da vida enquanto elementos autônomos. Neste sentido, a existência da propriedade privada do solo urbano vai revelando uma função econômica como realização continuada do valor; uma função jurídica que a realiza enquanto direito garantido pela constituição federal que torna inquestionável sua existência e uma função social e neste nível a existência da propriedade privada da terra realiza a desigualdade que está na base do desenvolvimento da sociedade capitalista (Carlos, 2007, p.112).
\end{abstract}

\title{
2. Os megaeventos esportivos como formas de reestruturação espacial
}

Tem sido possível observar que o processo de mercantilização das grandes cidades se aprofunda atualmente, dentro da lógica do neoliberalismo e do capital financeiro. Esse processo tende à homogeneização do espaço local produzido em alinhamento com práticas similares realizadas no nível distante (Lefebvre, 2001) ou global, através das parcerias entre o Estado e as empresas privadas - notadamente as construtoras e grandes incorporadoras imobiliárias. As ações estatais são direcionadas para atender pedaços selecionados dentro das cidades, fragmentos que se transformam em centralidades que concentram tecnologia e serviços similares.

A produção dessas centralidades, que se constituem dentro de uma hierarquização espacial, aprofunda as desigualdades socioespaciais, colocando em evidência a segregação de grande parte da população moradora dessas cidades que são, muitas vezes, removidas de seus locais de moradia e vivência diária para proporcionar as reestruturações urbanas, apresentadas dentro de um discurso estatal de crescimento e de oportunidades iguais para todos. Como já salientava Bensaïd (2008, p.31), "o estado estrutura um campo político específico, uma relação de forças particular, uma linguagem própria do conflito. Os antagonismos sociais manifestam-se aí num jogo de mudanças e de condensações, de alianças e oposições".

Através de um discurso que justifica uma representação das cidades como sujeitos sociais, são postos em prática operacionalizações de fragmentos espaciais selecionados, produzindo uma mercantilização das cidades, que devem agora "competir" dentro de um mercado global para receberem aportes de investimento, especialmente estrangeiros, o que tenciona ainda mais os conflitos entre o espaço produzido e o espaço vivido (Lefebvre, 2002), a dominação e a apropriação. 0 espaço urbano, nesse cenário, se torna cada vez mais uma mercadoria, que é fragmentado para atender aos interesses específicos do capital, principalmente através da elaboração e implantação de grandes projetos urbanos homogeneizantes, com intervenções que visam a "recuperação" e "revitalização" de espaços que interessam para o sistema de valorização atual.

Como discute Harvey (2005), esses projetos urbanos se implementam dentro de políticas públicas voltadas para planos de ordenação urbana nas grandes cidades pautados na forma do empreendedorismo. Nesse sentido, as cidades adotariam modelos de gestão que visam somente à 
promoção de projetos que possam atrair o capital. Pautadas nos modelos dos planos estratégicos, os governos das cidades tenderiam cada vez mais a lidar com seus problemas da mesma forma que as corporações privadas, na tentativa de tornar as cidades, empresas.

Esse modelo de política pública, ou de planejamento urbano pensado através dos chamados planos estratégicos, com suas bases voltadas ao mercado privado, tem sua origem nos grandes centros mundiais a partir da reestruturação do sistema capitalista nas décadas de 70 e 80, com raízes em modelos de planejamento norte-americanos de "empresariamento urbano" (Harvey, 2014), que visam a adoção de diretrizes e medidas empresariais para atingir um ordenamento espacial nas cidades.

\begin{abstract}
Em outras palavras, a abordagem "administrativa", tão característica da década de 1960, deu lugar a formas de ação iniciadoras e "empreendedoras" nas décadas de 1970 e 1980. Nos anos recentes, em particular, parece haver um consenso geral emergindo em todo o mundo capitalista avançado: os benefícios positivos são obtidos pelas cidades que adotam uma postura empreendedora em relação ao desenvolvimento econômico. Digno de nota é que esse consenso, aparentemente, difunde-se nas fronteiras nacionais e mesmo nos partidos políticos e nas ideologias (Harvey, 2005, p.165).
\end{abstract}

Nesse cenário, as agências multilaterais como BIRD, ONU-Habitat e Banco Mundial exercem uma posição de definição de estratégias e posturas na produção de um modelo de cidade que deve ser seguido pelos governos que almejam a atração de investimentos de capital.

Dessa forma, dentro do contexto dos grandes projetos, é possível observar a dimensão cultural e o apelo à imagem das cidades, onde certas áreas são destacadas e "qualificadas" através da criação de signos, geralmente grandes obras arquitetônicas e de lugares de atração turística. E quando a cidade vira uma mercadoria à venda, o poder público torna-se mediador para a captação de megaeventos, por exemplo que, por sua vez, favorecem grandes empresas privadas, assegurando a lógica do planejamento estratégico, fragmentando cada vez mais os espaços das cidades e os tornando mais desiguais.

Nesse momento em que o deslocamento de capitais se volta para as metrópoles, a "disputa" entre cidades para sediar megaeventos se abre como possibilidade, e mesmo justificativa, para a realização de intervenções urbanas pontuais sobre fragmentos da cidade, intensificando processos de segregação socioespacial e trazendo à tona o conflito pelo espaço - como lugar de apropriação e uso em contraposição ao espaço como reprodução de valor e de valor de troca. "O espaço fragmentado, partido, valorizado pela ação do poder político, penetra na vida cotidiana, desestabilizando-a, redefinido o papel de cada habitante nos lugares da metrópole pela limitação ao uso do espaço" (Carlos, 2001, p.359).

A realização de grandes eventos esportivos, culturais ou tecnológicos durante alguns anos, tem sido a estratégia de muitos governos para atrair capitais internacionais e gerar maior produção e rentabilidade dentro do processo de reprodução capitalista ${ }^{1}$. Portanto, ao tornar as cidades mais "atraentes" para os investimentos estrangeiros, o megaevento também potencializa uma forma "esquizofrênica" de competição entre as cidades mundiais. Desde os Jogos Olímpicos de Verão realizado na cidade de Barcelona, na Espanha, em 1992, utilizada como referência de "sucesso" de renovação urbana, o poder público de diversos municípios tem investido na realização de megaeventos esportivos como um modelo a ser imitado, através principalmente da adoção e implementação dos planos estratégicos.

\footnotetext{
1 Estudos mais detalhados sobre impactos negativos e positivos de megaeventos esportivos podem ser encontrados nas pesquisas feitas por: LENSKY, Helen Jefferson. When winners are losers: Toronto and Sydney bids for the Summer Olympics. Journal of Sport and Social Issues, Vol.24, p.392-416, 1996; HILLER, Harry H. Assessing the Impact of Mega-Events a Linkage Model. Current Issues in Tourism, vol.1, n.1, 1998; PILLAY, Udesh; BASS, Orli. Mega-events as a response to poverty reduction: The 2010 FIFA World Cup and its Urban Development Implications. Urban Forum, Vol.19, n.3, p.329-346, 2008; entre outros.
} 
A cidade do Rio de Janeiro, por exemplo, segue esse modelo de "gestão" da cidade desde 1996 onde, dentre as inúmeras metas para a organização da cidade, já constava uma primeira tentativa para sediar as Olimpíadas de 2004, utilizando a justificativa de unir a cidade em prol de um objetivo em comum (Prefeitura, 1996) que visasse à dinamização da economia, estagnada desde a transferência da capital para Brasília, em 1960 (Abreu, 2013).

\begin{abstract}
O Plano Estratégico é apresentado como um instrumento capaz de construir o consenso político necessário à execução de grandes projetos que combinam objetivos de crescimento econômico e desenvolvimento urbano, a partir de determinados pressupostos básicos, dentre os quais: a aposta no futuro das cidades como centro terciário qualificado; o crescente protagonismo político das administrações locais face ao enfraquecimento dos Estados nacionais; a cooperação público-privada no financiamento de grandes intervenções urbanísticas; e a necessidade de construir e/ou modificar a imagem da cidade para projetá-la no exterior através do marketing que enfoque, sobretudo, um principal produto de venda, como por exemplo, turismo ou cultura. (Compans, 2013, p.1721-1722).
\end{abstract}

As tentativas da cidade do Rio de Janeiro na captação do megaevento olímpico se sucederam nos anos subsequentes, culminando na declaração do Brasil como sede da Copa do Mundo 2014 e da própria cidade do Rio de Janeiro como sede dos Jogos Olímpicos de Verão 2016.

As intervenções públicas e privadas no espaço que se seguiram nos anos conseguintes aos anúncios, causaram inúmeros processos de remoção de diversas comunidades, principalmente de baixo poder aquisitivo, em praticamente todas as cidades-sede da Copa do Mundo de 2014 ou dos Jogos Olímpicos Rio 2016 (Dossiês do Comitê Popular da Copa, 2014; Olimpíadas do Rio de Janeiro, 2016). Muitas dessas comunidades foram totalmente removidas, e seus moradores, considerados "invasores" de terras públicas ou privadas, saíram de suas casas e dos seus espaços de vivência cotidiana sem indenizações ou compensações financeiras. No entanto, algumas comunidades resistiram às remoções e conseguiram permanecer nos seus locais de residência, ou em outros casos, permaneceram nos espaços, mas com novas habitações, como apontam as diversas edições dos Dossiês.

A proposta desta pesquisa, portanto, é de justamente tentar desvelar os processos de resistência dos moradores de duas comunidades que foram diretamente afetadas pelas obras de estruturação urbana relacionadas aos megaeventos esportivos, através de uma perspectiva baseada no seu cotidiano. A tentativa será de pesquisar como esses lugares ficaram após os processos de reprodução dos espaços nas cidades-sede e como a vida cotidiana das pessoas foi modificada dentro do contexto das relações sociais que se estabelecem a partir do local de moradia.

Foram escolhidas duas comunidades para o desenvolvimento da pesquisa: a Vila da Paz, que se localiza no bairro de Itaquera, na cidade de São Paulo, cujos moradores foram ameaçados de remoção para a construção do entorno da Arena Corinthians para a Copa do Mundo 2014 e que, atualmente, sofrem novo processo de tentativa de remoção pelo poder público - agora para passagem de um corredor de ônibus 2 . E a Vila Autódromo, comunidade localizada no bairro da Barra da Tijuca, no Rio de Janeiro, que foi parcialmente removida durante os preparativos para os Jogos Olímpicos Rio 2016, permanecendo no local cerca de 20 famílias 3 .

O objetivo da pesquisa é entrar em contato direto com o cotidiano dos entrevistados, voltando-se para a compreensão de processos, fatos diários e particulares dos grupos específicos, também através de análise por pesquisa participante.

A escolha por essas comunidades específicas se justifica no fato de os moradores terem resistido

\footnotetext{
2 Análise completa disponível em: https://observasp.wordpress.com/2017/05/16/prefeitura-de-sp-volta-a-ameacar-comunidade-da-pazsem-apresentar-justificativas-tecnicas / - Acesso em 16/05/2017.

3 Sobre todo o processo de remoção pelo qual passou a comunidade, consultar Previatti, 2016, disponível em: http://www.teses.usp.br/teses/disponiveis/100/100134/tde-24082016-101115/pt-br.php.
} 
aos processos de remoções perpetrados pelo poder público e terem conseguido permanecer em seus locais de habituais de moradia, seja de forma total ou parcial. É importante salientar que essas duas comunidades já sofriam tentativas de remoção que antecederam a realização dos megaeventos esportivos em si. No entanto, para o escopo dessa pesquisa, serão consideradas as remoções sofridas pelas famílias através de ações do poder público ou da iniciativa privada, especificamente aquelas ligadas às obras urbanas de construção de equipamentos ou de obras ligadas à mobilidade, relacionadas à realização da Copa do Mundo 2014 e dos Jogos Olímpicos Rio 2016 até o presente.

Compreender como se deram esses processos de resistência dos moradores, o histórico de luta, os sujeitos e agentes envolvidos, se torna fundamental na busca pela problemática do processo de reprodução dos espaços nas cidades brasileiras na contemporaneidade, principalmente no que tange à utilização dos megaeventos como justificativa para as transformações socioespaciais.

\section{O processo de resistência - uma análise teórica}

Partindo do pressuposto de que a moradia no contexto político, econômico e social capitalista significa de forma indissociável a propriedade privada, o objetivo principal da pesquisa será analisar o cotidiano e a mobilização social de moradores de duas comunidades brasileiras, uma localizada na cidade de São Paulo e uma na cidade do Rio de Janeiro, que resistiram à processos de remoção intensificados durante a realização da Copa do Mundo 2014 e dos Jogos Olímpicos Rio 2016, no que se refere à habitação e ao conflito pelo espaço urbano.

Julga-se necessária uma abordagem que considere a segregação socioespacial e a apropriação do espaço urbano através das resistências, que evidenciam a dialética constante do processo de produção espacial entre o valor de uso e o valor de troca. As resistências são entendidas, primeiramente, como uma forma de negação aos processos que compõem a segregação socioespacial (Ribeiro, 2012). Nesse sentido, entende-se que as resistências não são necessariamente formas organizadas de reivindicação ou de demandas por políticas públicas, mas intrínsecas a um modelo de negação da própria vida urbana. Para muitas pessoas, o fato de permanecer na cidade, mesmo que em moradias precárias e em locais onde não haja infraestrutura urbana, já pode ser considerado uma forma de resistência.

Por essa perspectiva, é possível compreender o processo de apropriação do espaço através do uso cotidiano e das práticas sociais que se realizam no plano do vivido, que contrapõem os processos de mercantilização da terra urbana, mas que são, também, contraditórios em sua essência, visto que, dentro do sistema capitalista, o direito à moradia se pauta sobre a propriedade privada. Simultaneamente, estudar os conflitos pela moradia urbana pressupõe entender que os próprios processos cotidianos do vivido estão pautados pelo mercado, pela troca e pelo valor que adquire socialmente a propriedade privada.

Segundo reflexões de Ribeiro (2012), a transgressão do morar é o primeiro momento da luta de resistência, tendo em vista a necessidade do próprio ser-humano em habitar um local para o descanso do corpo. Em função de todo o processo de segregação socioespacial historicamente construído nas grandes cidades brasileiras, a transgressão para ter onde morar se apresenta para muitas pessoas como a forma possível, dentro do processo de produção capitalista, que cada vez mais permeia todos os momentos da vida cotidiana.

Inicialmente, a resistência no urbano está no momento de recusa à expulsão dos lugares ocupados. Antes, esses lugares não representavam interesse ao mercado imobiliário e agora, incorporados aos novos circuitos de valorização, exigem estar "vazios". A prática do Estado é pulverizar/expulsar os moradores ali alocados e que produziram nele as únicas possibilidades da forma de morar. [...] A resistência está em não ceder porção da cidade aos negócios urbanos, mesmo que esteja mergulhada em ambiguidades (Ribeiro, 2012, p.15). 
A prática socioespacial dos moradores das cidades está circunscrita ao próprio modelo do sistema capitalista atual, com a separação dos lugares de lazer, trabalho e habitação. Nessa perspectiva, para uma parcela da população brasileira, "viver na cidade capitalista significa praticar a transgressão como primeira resistência para, no processo de descoberta, resistir às expropriações em outro nível" (Ribeiro, 2012, p.153).

Nesse sentido, para se entender como se realizam esses processos, pelo viés de quem vivencia cotidianamente a forma de transgressão do morar como primeira resistência, é necessário compreender a violência do processo de urbanização e a propriedade privada como forma hegemônica para a habitação.

$\mathrm{Na}$ análise de Zibechi (2015) as classes populares latino-americanas criaram historicamente formas de resistência especialmente relacionadas às formas de morar nas grandes cidades, discutindo a formação dos novos territórios urbanos, que o autor classifica como emancipatórios.

Alguns desses espaços urbanos de resistência pesquisados por ele em cidades da América Latina, nasceram da luta de pequenas comunidades indígenas ou rurais para manter suas tradições culturais e modos de vida que não eram então pautados pelo capitalismo, ou seja, pela mercadoria. Essas populações teriam, em algum momento histórico, migrado para as áreas urbanas em decorrência do próprio processo capitalista de produção, que foi gradualmente adentrando as áreas rurais e "expulsando" as pessoas de suas áreas de residência. Exemplos desse processo são os grandes latifúndios e o monopólio agrário, que acabam por minar pequenos proprietários agrícolas de suas formas de sobrevivência, até então baseadas na subsistência e na troca de pequenos excedentes em comunidades locais. Essas populações rurais migram para as cidades e, sem terem condições econômicas de pagar por moradia, acabam por ocupar áreas mais distantes dos centros das cidades, construindo na transgressão do processo de morar, novos espaços, pautados em princípios da "autonomia, autogestão e autodeterminação" (Zibechi, 2015, p.100). Para o autor, nasce com esses territórios o conflito social pelo espaço nas cidades, marcado pela presença negativa de elementos da cultura hegemônica, como a falta de serviços básicos, por exemplo.

A reflexão do autor converge para o processo de como essa primeira forma de resistência, a imediata necessidade de morar e de viver, vai dando lugar, dentro do processo de luta, a formas de conscientização das relações políticas e econômicas. "A estratégia territorial se desdobra de dentro para fora, numa relação de imanência, surgindo aqui e ali nos interstícios e nas brechas da dominação do capital (Zibechi, 2015, p.157). São, nesse aspecto, para o autor, locais onde é possível pensar no nascimento de uma nova estrutura social.

Nesse sentido, transplantando alguns dos apontamentos do autor para a realidade de grande parte dos habitantes das cidades brasileiras, as ocupações e os loteamentos, denominados pelo poder público e pela classe hegemônica como "irregulares", se tornam formas que, inicialmente, podem ser consideradas como transgressões à legislação urbana, como uma forma de inserção precária dentro do próprio processo de produção. Quando esses locais habitados por essas populações apresentam um potencial de valorização para o mercado imobiliário, inserido, como já discutido, dentro do próprio processo de reprodução do sistema capitalista e no contexto da "disputa" entre os governos das cidades pela atração de investimentos, o Estado intervém para a desocupação desses espaços e para os processos de demolição e "revitalização".

É viável refletir que a própria vida cotidiana desses moradores se realiza como uma transgressão diária: é preciso superar todos os dias os obstáculos que se apresentam na ausência consentida do Estado, principalmente no que diz respeito aos serviços públicos básicos tais como saneamento, luz elétrica, transporte público; é preciso lidar com preconceitos e estigmas sociais, que invariavelmente associam áreas carentes à violência e criminalidade; é, portanto, tornar diária a luta pelo direito de morar na cidade.

Nessa discussão, é possível compreender que o processo de luta pela permanência dessas populações nos locais que foram primordialmente ocupados para morar e que, com o transcorrer do 
tempo, passaram também a ser onde essas pessoas puderam reproduzir a vida através de relações sociais mais comunitárias, já estava presente desde o começo, desde a transgressão primeira do morar, o que torna ainda mais violento, do ponto de vista humano e social, a forma como se produz o urbano nas grandes cidades.

A hipótese que se coloca é de que o processo de luta e de resistência é parte constitutiva do processo de produção das metrópoles brasileiras na contemporaneidade e podem transformar o sentimento de pertencimento dos moradores no plano do imediato, tornando possível a perspectiva do possível, não somente do modo de se habitar, mas de se viver no plano intermediário e até mesmo, em novas formas de construção da vida no plano distante.

O objetivo geral da pesquisa é analisar como, durante o processo de mobilização do espaço urbano para a reprodução do capital- as transgressões sociais pelo morar abrem a potencialidade para a compreensão social da condição urbana, que, contraditoriamente, só pode ser efetivamente assimilado pelo processo de reprodução do espaço urbano através do cotidiano, da reprodução da vida social.

Nessa discussão, será necessário analisar o cotidiano e a mobilização social dos moradores das duas comunidades propostas, no que tange à habitação e ao conflito pelo espaço urbano, bem como identificar quais foram os argumentos, leis e projetos apresentados pelo poder público que justificassem a remoção das habitações e sua relação ou não com a realização dos megaeventos esportivos.

Da mesma forma, será fundamental averiguar quais foram as estratégias empregadas pelos moradores das comunidades afetadas para sua permanência, bem como as utilizadas pelo poder público e empresas privadas para a realização das remoções e analisar as transformações morfológicas, arquitetônicas e viárias - produzidas pelas obras de infraestrutura dos megaeventos, principalmente seus impactos na habitação dos moradores e sua mobilidade espacial.

Partindo de uma análise das dinâmicas e transformações do(s) lugar(es) e do cotidiano dos moradores das duas comunidades afetadas pelas obras dos megaeventos esportivos, no nível próximo, a pesquisa buscará estabelecer uma relação com os outros níveis: o intermediário, representado pela cidade e o distante, representado pelo espaço mundial na reprodução atual do capitalismo, tendo por pressuposto de que os níveis e dimensões estão interligados uns aos outros, tornando a proposta metodológica fundamental para o desvendamento das contradições socioespaciais a que se propõe esta pesquisa.

Quando se alarga, saindo do lugar para o encontro de sujeitos que padecem dos mesmos confrontos na cidade, a prática socioespacial se estende, porque, no desenvolvimento da resistência primeira, as ações exigem a articulação com o outro na produção de uma identidade que não apenas se remete ao lugar, mas está articulada ao nível intermediário, isto é, ao da cidade (Ribeiro, 2012, p.156).

Tendo, portanto, definido que a segregação socioespacial é produto do modo de reprodução das cidades, é possível propor que o próprio processo de resistência abre a potencialidade para a compreensão social da condição urbana, que só pode ser efetivamente assimilado pelo processo de reprodução do espaço urbano através do cotidiano, da reprodução da vida social.

Dessa forma, apreende-se que é imperativo uma discussão sobre as resistências por habitação, dentro de um contexto historicamente produzido, e tendo por premissa que o próprio processo de resistência é a forma possível encontrada por muitos moradores das metrópoles, na busca por uma utopia de transformação da própria relação social e do modo como se produzem os espaços. 


\section{Referências}

ABREU, Maurício de A. Evolução Urbana do Rio de Janeiro. Rio de Janeiro: Instituto Pereira Passos, $4^{\mathrm{a}}$ edição, 2013.

ALVAREZ, Isabel Aparecida Pinto. A reprodução da metrópole: o projeto Eixo Tamanduatehy. Tese apresentada ao Programa de Pós-graduação em Geografia Humana do Departamento de Geografia da Universidade de São Paulo para obtenção do título de doutor em Geografia, 2008.

As políticas espaciais contemporâneas e a reprodução do capital e do urbano. In: Revista Cidades, vol.9, no 16, p.62-85, 2011. Disponível em: http://revista.fct.unesp.br/index.php/revistacidades/article/viewFile/2373/2116.

A produção e reprodução da cidade como negócio e segregação. In: A cidade como negócio. Org.: Ana Fani Alessandri Carlos, Danilo Volochko e Isabel Pinto Alvarez. São Paulo: Contexto, p.65-79, 2015.

BENSAIID, Daniel. Resistencias: ensayo de topologia general. El viejo Topo, 2001.

Os irredutíveis: teoremas da resistência para o tempo presente. São Paulo: Boitempo, 2008.

CARLOS, Ana Fani Alessandri. Espaço-tempo na metrópole: a fragmentação da vida cotidiana. São Paulo: Contexto, 2001.

O espaço urbano. Novos escritos sobre a cidade. São Paulo: FFLCH, 2007. A condição espacial. São Paulo: Ed. Contexto, 2011.

Metageografia: ato de conhecer a partir da Geografia. In: Crise Urbana. Org.: Ana Fani Alessandri Carlos. São Paulo: Contexto; p. 9-23, 2015.

DEBORD, Guy. A sociedade do espetáculo. Rio de Janeiro: Contraponto, 1997.

DOSSIÊ VIOLAÇÕES, 2014. Articulação Nacional dos Comitês Populares da Copa e Olimpíadas. Megaeventos e Violações dos Direitos Humanos no Brasil, 2014. Disponível em: http://www.portalpopulardacopa.org.br/index.php?option=com_k2\&view=item\&id=663:dossi\%C3 \%AA-nacional-2014. Acesso em dezembro de 2014.

DOSSIÊ VIOLAÇõES, 2015. Articulação Nacional dos Comitês Populares da Copa e Olimpíadas. Megaeventos e Violações dos Direitos Humanos no Rio de Janeiro, 2015. Disponível em: https://issuu.com/mantelli/docs/dossiecomiterio2015_issuu_01.

HARVEY, David. A Produção Capitalista do Espaço. São Paulo: Annablume, 2005.

O novo imperialismo. São Paulo: Loyola, 2014.

LEFEBVRE, Henri. A re-produção das relações de produção. Publicações Escorpião, Porto: Antaropos, 1973.

O direito a cidade. São Paulo: Editora Centauro, 2001.

A revolução urbana. Belo Horizonte: Ed. UFMG, 2002.

Espaço e política. 0 direito à cidade II. Belo Horizonte: Ed. UFMG, 2016.

MARX, Karl. O Capital: crítica da economia polícia. v.1, t.1-2 - 0 processo de produção do capital; v.2 0 processo de circulação do capital; v.3, t.1-2 - 0 processo global da produção capitalista. São Paulo: Ed. Nova Cultural (Os Economistas), 2ª edição, 1985-1986.

O Capital. Livro I, capítulo IV (inédito), 1a edição. São Paulo: Livraria Editora Ciências Humanas Ltda, 1978. 
PREFEITURA do Rio de Janeiro. Plano Estratégico da cidade do Rio de Janeiro - Rio Sempre Rio. Rio de Janeiro: Prefeitura, 1996.

PREVIATTI, Carine Botelho. Segregação Socioespacial na realização dos Jogos Olímpicos Rio 2016 na região da Barra da Tijuca - RJ: Comunidade Vila Autódromo. Dissertação de Mestrado, 2016.

RIBEIRO, Fabiana Valdoski. A luta pelo espaço: da segurança da posse à política de regularização fundiária de interesse social em São Paulo. São Paulo, 2012.

RODRIGUES, Arlete Moysés. Os Megaeventos na produção e reprodução do espaço urbano. GeoTextos, Vol.9, n.2, p.13-25, 2013.

SANTOS, Cesar Ricardo Simoni. Dos negócios na cidade a cidade como negócio: uma nova sorte de acumulação primitiva do espaço. In: Revista Cidades, v.3, n.5, p.101-122, 2006.

A Fronteira Urbana: urbanização, industrialização e mercado imobiliário no Brasil. São Paulo: Annablume, 2015.

SCIFONI, Simone. Lugares de memória operária na metrópole paulistana. Revista GEOUSP - Espaço e Tempo. São Paulo, n. 33, p. 98-110, 2013.

SERPA, Angelo. Teoria das representações em Henri Lefebvre: por uma abordagem cultural e multidimensional da geografia. Revista GEOUSP - Espaço e Tempo. São Paulo, vol. 18, n. 3, p. 487-495, 2014.

ZIBECHI, Raúl. Territórios em resistência: cartografia política das periferias urbanas latinoamericanas. Rio de Janeiro: Consequência, 2015.

ZIMBALIST, Andrew. Circus maximus: the economic gamble behind hosting the Olympics and the World Cup. Massachusetts: The Booking Institution, 2015.

ZIMBALIST, Andrew (Org.). Rio 2016: Olympic Myths, Hard Realities. Washington, D.C.: The Brookings Institution, 2017 - ebook Kindle. 